\title{
Article \\ Influence of Root Canal Sealers and Obturation Techniques on Vertical Root Fracture Resistance. An In Vitro Experiment
}

\author{
Mazen F. Alkahtany ${ }^{1}$, Khalid H. Almadi ${ }^{1}$, Fahad A. Alahmad ${ }^{2}$, Abdullah M. Alshehri ${ }^{2}$, \\ Abdulrahman A. AlSwayyed ${ }^{2}$, Omar M. AlZahran ${ }^{2}$, Ali AlHadan ${ }^{3}$, Abdulaziz S. Almustafa ${ }^{3}$, Fahim Vohra ${ }^{4}$ and \\ Tariq Abduljabbar ${ }^{4, *}$ \\ 1 Department of Restorative Dental Science, Division of Endodontics, College of Dentistry, King Saud \\ University, Riyadh 11545, Saudi Arabia; malkahtany@ksu.edu.sa (M.F.A.); kalmadi@ksu.edu.sa (K.H.A.) \\ 2 Dental Intern, College of Dentistry, King Saud University, Riyadh 11545, Saudi Arabia; \\ fahad.alahmed96@gmail.com (F.A.A.); A.alshehri.dent@gmail.com (A.M.A.); \\ Abo.mohannad1996@gmail.com (A.A.A.); Omardentt@gmail.com (O.M.A.) \\ 3 Department of General Dentistry, College of Dentistry, King Saud University, Riyadh 11545, Saudi Arabia; \\ aahdn87@gmail.com (A.A.); abdaziza@gmail.com (A.S.A.) \\ 4 Department of Prosthetic Dental Science, College of Dentistry, King Saud University, \\ Riyadh 11545, Saudi Arabia; fvohra@ksu.edu.sa \\ * Correspondence: tajabbar@ksu.edu.sa; Tel.: +966-1467-7444; Fax: +966-1467-8639
}

Citation: Alkahtany, M.F.; Almadi, K.H.; Alahmad, F.A.; Alshehri, A.M.; AlSwayyed, A.A.; AlZahran, O.M.; AlHadan, A.; Almustafa, A.S.; Vohra, F.; Abduljabbar, T. Influence of Root Canal Sealers and Obturation Techniques on Vertical Root Fracture Resistance. An In Vitro Experiment. Appl. Sci. 2021, 11, 8022. https:// doi.org/10.3390/app11178022

Academic Editor: Bruno Chrcanovic

Received: 27 July 2021

Accepted: 24 August 2021

Published: 30 August 2021

Publisher's Note: MDPI stays neutral with regard to jurisdictional claims in published maps and institutional affiliations.

Copyright: (c) 2021 by the authors Licensee MDPI, Basel, Switzerland. This article is an open access article distributed under the terms and conditions of the Creative Commons Attribution (CC BY) license (https:// creativecommons.org/licenses/by/ $4.0 /)$.

\begin{abstract}
The aim of the present study was to determine the vertical root fracture (VRF) resistance of roots obturated with TotalFill BC Sealer and AH Plus sealer using lateral condensation and single cone techniques in comparison to untreated controls. Sixty single rooted mandibular premolars were sectioned and divided into six groups. Ten teeth were left untreated (positive control-Gp 1) and fifty teeth were cleaned and shaped. Ten root specimens were left unfilled (negative control-Gp 2) and the remaining roots were divided into 4 groups. Gp 3, GP and AH Plus sealer (AH Plus) using the cold lateral compaction (LC) technique; Gp 4, GP and AH Plus using the Single Cone (SC) technique; Gp 5: TotalFill GP and TotalFill BC sealer using the LC technique; Gp 6: TotalFill GP and TotalFill BC sealer with SC. VRF was performed for all specimens using a universal testing machine. Analysis of variance (ANOVA) and Tukeys post-hoc multiple comparison test was used to compare the means among tested study groups. Group 1 (positive control) displayed the highest fracture resistance $(946.61 \pm 166.465 \mathrm{~N})$; however, the lowest fracture strength was demonstrated by the specimens in group 2 (negative control) $(433.31 \pm 129.350 \mathrm{~N})$. Specimens treated with $\mathrm{AH}$ plus using different obturation techniques (group 3 and 4) showed comparable outcomes $(p>0.05)$. Similarly, specimens treated with TotalFill BC sealer with different obturation techniques showed statistically similar outcomes $(p>0.05)$. It was also observed that specimens in groups $3,4,5$ and 6 demonstrated comparable outcomes of fracture strength $(p>0.05)$. The use of TotalFill-BC sealer showed similar vertical root fracture resistance as $\mathrm{AH}$ plus sealer in root canal treated teeth. Use of total fill-BC and AH Plus sealer in root canal treatment showed vertical root fracture resistance comparable to untreated natural teeth (positive controls).
\end{abstract}

Keywords: sealers; vertical fracture; root filling; fracture resistance; obturation technique

\section{Introduction}

An endodontically treated tooth is more prone to vertical root fracture (VRF) due to multiple contributing factors, i.e., caries or trauma, access cavity preparation, root canal instrumentation, lateral condensation force during obturation, preparation of post space and functional occlusal loading, which leads to failure [1]. VRF is considered one of the most common complications of endodontic treatment, eventually leading to extraction of the tooth [2]. It can occur during or after the root canal treatment (RCT) due to compromised tooth structure. Therefore, reinforcement of the remaining tooth structure 
is considered as an important aspect of endodontic treatment [3]. Available literature revealed that bonding of root filling with the radicular dentin strengthens the tooth as well as increases its fracture resistance $[4,5]$.

Cleaned and shaped root canals obturated with Gutta-percha (GP) and root canal sealer is considered as the gold standard [6]. GP lack the capability to reinforce the weakened root structure because of their low modulus of elasticity [7]. Therefore, a root canal sealer is considered as a joint between a canal and a filling material. An ideal root canal sealer should possess the property of filling the apical and lateral empty spaces and irregularities between GP points and root dentin walls [8]. Moreover, it was also assumed that sealer, which exhibits adhesion to the canal dentin, results in reinforcement of the tooth and increases the fracture toughness against the occlusal load by conserving the integrity at the sealer-dentin interface [9]. Therefore, multiple research methodologies have introduced different canal sealers [10].

Among different sealers used recently, AH Plus (resin-based root canal sealer) is considered as a material of choice for canal obturation due to ease of handling, good mechanical properties, wettability and excellent sealing property [11]. Furthermore, it also exhibits less polymerization shrinkage, low solubility, and a high degree of stability on storage [12]. Studies have suggested that AH Plus sealer results in increased fracture resistance of endodontically treated teeth $[12,13]$. However, a few studies presented contradictory findings $[9,14]$.

TotalFill BC Sealer on the other hand is a calcium-silicate based bio-ceramic root canal sealer. It is dispensed in a premixed ready-to-use injectable form that sets in the presence of water, possesses excellent antimicrobial ability, higher $\mathrm{pH}$, and exceptional biocompatibility. TotalFill BC sealer can easily penetrate the dentinal tubules due to presence of nanoparticles. In addition, it does not shrink while setting and demonstrates excellent physical properties. Available literature revealed that calcium silicate based sealer reinforces the tooth structure against the VRF and strengthens the tooth. A study conducted by Ghoneim et al. [15] and Sağsen et al. [16] showed that bioceramic-based sealer (BC sealer) has the potential to increase the root fracture resistance [17]. In contrast, Celikten et al. reported that BC sealer has a significantly lower mean value for fracture than the control group [18].

From the available indexed literature it was found that sufficient data related to the effect of AH Plus sealer on the fracture resistance of root canal treated tooth are available. However, data on the influence of TotalFill BC sealer on fracture resistance of root treated teeth in comparison to commonly used sealers are limited. Therefore, it was hypothesized that there will be no difference in fracture resistance of roots obturated with TotalFill BC Sealer and AH Plus sealer. It was also hypothesized that there will be no difference in root fracture resistance when two different obturation techniques, i.e., lateral condensation and single cone technique, are employed. Thus, the aim of the present study was to determine the fracture resistance of roots obturated with TotalFill BC Sealer and $\mathrm{AH}$ Plus sealer using lateral condensation and single cone techniques in comparison to untreated controls.

\section{Materials and Methods}

\subsection{Specimen Preparation}

A total of sixty freshly extracted single rooted mandibular premolars were collected over a period of 3 months. All the teeth were stored in Hank's balanced salt solution (HBSS) till further use. All the specimens were cleaned, sterilized and made ready to examine under stereo-microscope (Stemi 2000-C, Zeiss, Wetzlar, Germany) at 50× magnification in order to exclude teeth with open apices, root caries, cracks and/or fractured roots. Any tooth with a resorption defect or previous root canal treatment was excluded. A pre-operative radiograph was taken both buccolingually and mesiodistally to confirm the presence of a single canal. De-coronation was performed at the level of CEJ with the help of a high speed hand-piece with a wheel diamond bur in order to standardize $13 \mathrm{~mm}$ of root length. The methodology outline is presented in Figure 1. 


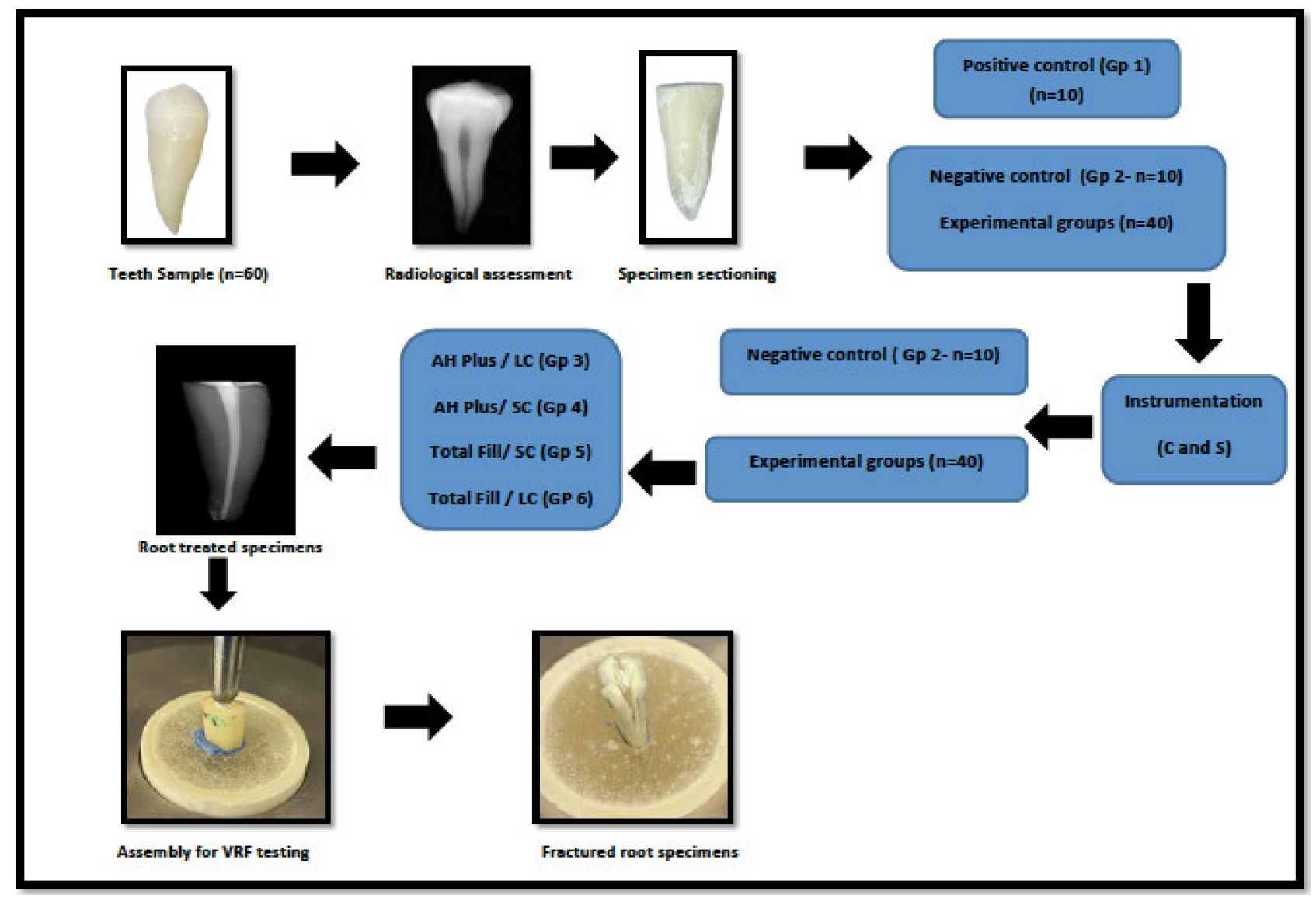

Figure 1. Flow chart for study methodology.

\subsection{Treatment and Study Groups}

Ten samples were kept un-instrumented as positive controls (group 1). A size \#15 K patency file was used to determine the correct working length (WL). For fifty specimens, the $\mathrm{k}$ file was placed in the canal until it extrudeed the apex and then the file was pulled $1 \mathrm{~mm}$ shorter to the apex. Fifty specimens were then prepared using the crown-down technique by Profile rotary system up to \#40/0.04 taper file (excluding positive control specimens-group 1). Between each instrumentation, constant irrigation was performed with $2.5 \% \mathrm{NaOCl}(1 \mathrm{~mL})$. After completion of the canal preparation, a final rinse was performed with $2.5 \% \mathrm{NaOCl}(2 \mathrm{~mL})$ for $1 \mathrm{~min}$ followed by $2 \mathrm{~mL} \mathrm{17 \%} \mathrm{EDTA} \mathrm{for} 1 \mathrm{~min}$ and $10 \mathrm{~mL}$ distilled water. Root canal surfaces were dried using paper points and were further divided into 5 groups $(n=10)$ based on instrumentation and obturation techniques.

Group 1 (Positive control): Samples were left un-instrumented and unfilled.

Group 2 (Negative control): Roots were instrumented and left unfilled.

Group 3: GP and AH Plus sealer using cold lateral compaction technique.

Group 4: GP and AH Plus sealer using Single Cone technique

Group 5: TotalFill GP and TotalFill BC sealer using cold lateral compaction technique Group 6: TotalFill GP and TotalFill BC sealer using Single Cone technique.

After completing obturation, periapical radiographs were exposed to assess the quality of root filling. Any root with inadequate obturation was excluded and replaced with a newly prepared specimen. The access cavity was closed using temporary filling (3M $\mathrm{M}^{\mathrm{TM}}$ Cavit $^{\mathrm{TM}}$ ). The specimens were kept at $37{ }^{\circ} \mathrm{C}$ and $100 \%$ humidity for 2 weeks to allow complete setting of the sealer.

\subsection{Specimen Testing}

To simulate the periodontal attachment, the specimen's root surface was coated with a thin-layer of polyvinylsiloxane (PVS) impression material up to $2 \mathrm{~mm}$ apical to the coronal 
end of the root. All of the roots were mounted perpendicularly in a poly-vinyl ring filled with self-cure acrylic resin (Opti-Cryl, South Carolina, Columbia) exposing $2 \mathrm{~mm}$ from the root (cervical). Root fracture resistance was assessed using a universal testing machine (UTM) (Lloyds, LF, plus, Ametek Inc., Great Britain, UK). All of the samples were placed in the lower plate of the testing machine and in the upper part a custom-made metal spreader with a diameter of $0.8 \mathrm{~mm}$ was secured. The tip was oriented in the center of the canal orifice and force was applied vertically to the long axis of the root at a crosshead speed of $0.5 \mathrm{~mm} / \mathrm{min}$ until root fracture. A drop in $>25 \%$ of applied force was observed when the fractures occurred. The amount of load necessary for root fracture was recorded in Newtons (N).

\subsection{Statistical Analysis}

Data related to fracture strength was analyzed using Statistical package for the social sciences (SPSS V.25, IBM, New York, NY, USA). Normality was assessed using the Kolmogorov-Smirnov test. One-way analysis of variance (ANOVA) and Tukey's post-hoc multiple comparison test were used to compare the means among tested study groups.

\section{Results}

The mean and standard deviations of fracture resistance among the investigated groups are presented in Table 1.

Table 1. Means and SD of vertical root fracture resistance among study groups.

\begin{tabular}{cccc}
\hline Study Group & Mean & SD & $\begin{array}{c}\text { ANOVA } \\
(\boldsymbol{p} \text { Value })\end{array}$ \\
\hline 1. Positive control & 946.61 & 166.46 & \\
2. Negative control & 433.31 & 129.35 & \\
3. GP-AH Plus-LC & 733.71 & 232.57 & \\
4. GP-AH Plus-SC & 752.77 & 120.58 & \\
5. Totalfill GP-BC-LC & 701.11 & 65.29 & \\
6. Totalfill GP-BC-SC & 797.46 & 204.55 & \\
\hline
\end{tabular}

SD. Standard deviation, LC. Cold lateral compaction, SC. Single cone, GP. Gutta Percha.

The Kolmogorov-Smirnov test displayed normal distribution of data. Specimens of group 1 (positive control) displayed the highest fracture resistance $(946.61 \pm 166.465 \mathrm{~N})$; however, the lowest fracture strength was demonstrated by the specimens in group 2 (negative control) $(433.31 \pm 129.350 \mathrm{~N})$. ANOVA revealed that fracture strengths among study groups were statistically significant $(p \leq 0.05)$.

Individual comparisons among all the investigated groups established that group 2 displayed significantly lower fracture strength among all experimental groups. Group 1 (positive control) showed higher fracture strength than groups $2(p<0.01)$ and $5(p=0.0)$; however, it was comparable to groups $3(p>0.05), 4(p=0.10)$ and $6(p=0.33)$, respectively. Specimens treated with $\mathrm{AH}$ plus using different obturation techniques (group 3 and 4 ) showed comparable outcomes $(p=0.99)$. Similarly, specimens treated with TotalFill BC sealer with different obturation techniques showed statistically similar outcomes $(p=0.77)$. It was also observed that specimens in groups 3, 4, 5 and 6 demonstrated comparable outcomes of fracture strength $(p>0.05)$ (Table 2$)$. 
Table 2. Statistical comparison of root fracture resistance among study groups (Tukey's post hoc test).

\begin{tabular}{ccc}
\hline Study Groups & Group Comparison & $p$ Value \\
\hline & 1 vs 2 & 0.0000 \\
1. Positive control & 1 vs 3 & 0.0541 \\
& 1 vs 4 & 0.1003 \\
& 1 vs 5 & 0.0166 \\
& 1 vs 6 & 0.3300 \\
\hline 2. Negative control & 2 vs 3 & 0.0017 \\
& 2 vs 4 & 0.0007 \\
& 2 vs 5 & 0.0069 \\
3. GP-AH Plus-LC & 2 vs 6 & 0.0001 \\
\hline 4. GP-AH Plus-SC & 3 vs 4 & 0.9998 \\
& 3 vs 5 & 0.9976 \\
\hline 5. Totalfill GP-BC-LC & 3 vs 6 & 0.9508 \\
6. Totalfill GP-BC-SC & 4 vs 5 & 0.9800 \\
\hline
\end{tabular}

LC. Cold lateral compaction, SC. Single cone, GP. Gutta Percha.

\section{Discussion}

The present study was based on the hypothesis that there will be no difference in fracture resistance of root canals obturated with TotalFill BC Sealer and AH Plus sealer. It was also hypothesized that there will be no difference in fracture resistance when two different obturation techniques, i.e., lateral condensation and the single cone technique were used. Thus, the postulated hypothesis was accepted as experimental groups in which root canals were obturated using different sealers (TotalFill sealer and AH Plus sealer) and different techniques (lateral condensation technique and Single Cone technique) showed comparable fracture resistance outcomes. A multitude of reasons are responsible for such outcomes, including the adhesive properties of the sealer, bioactivity of sealers, instrument type and instrumentation methods, and root dentin anatomy.

In the present study, in order to avoid inter-operator variability, a single operator performed all procedures including root canal preparation, irrigation and obturation. Similarly, for root canal preparation, the crown down technique was adopted as it allows debris to be expelled from the canal orifice [19]. Moreover, further standardization was achieved by using AH Plus sealer, which is considered as a gold standard root canal sealer in dentistry [20].

A sealer is conceived as a joint created between radicular dentin and the root filling material [13]. Adhesion between an endodontic sealer and root dentin serves two important purposes [21]. Primarily, the root canal sealer gives a superior seal, which prevents coronal and apical leakage [22]. Secondly, it inhibits filling material displacement during restorative procedures. In the present study, it was found that the mean value of fracture loads of the positive control $(433.31 \pm 129.350 \mathrm{~N})$ was significantly lower than all other groups tested. The above findings can be associated with loss of radicular dentin thickness (RDT) and moisture due to canal instrumentation and the reinforcement effect by both sealers $[23,24]$.

It was also established that positive control specimens, in which no canal instrumentation performed displayed a fracture strength comparable to group 3 (AH plus sealer + Lateral condensation technique) $(733.71 \pm 232.572 \mathrm{~N}$ ), group 4 (AH plus sealer + Single Cone technique) $(752.77 \pm 120.587 \mathrm{~N})$, and group 6 (TotalFill sealer + Single Cone technique) $(797.46 \pm 204.557 \mathrm{~N})$. There are various justifications that are accredited to such an outcome. AH Plus sealer, being epoxy resin-based, unveils some desired proprieties, i.e., adhesion by forming a covalent bond between the open epoxide ring and exposed amino acids in the collagen [25]. Moreover, AH Plus possesses an excellent penetration ability into the surface micro-irregularities due its creeping property, which results in increased 
fracture strength $[11,26]$. This finding is in line with the results of the earlier stated studies by Sağsen et al. and Topçuoğlu et al., which suggested that obturation with $\mathrm{AH}$ plus root canal sealers are able to resist the fracture load equivalent to the sound tooth structure in which no canal preparation and filling was performed $[3,16]$. Similarly, the comparable fracture resistance demonstrated by the $\mathrm{BC}$ sealer in group 6 specimens to the positive control group can be explained by its property to produce hydroxyapatite, which leads to increased chemical bonding of sealer to the canal dentinal walls [11,27]. In addition, the presence of small "nanoparticles" and their ability to penetrate deeply into isthmuses, accessory canals and canal irregularities also justifies the higher fracture strength of TotalFill sealer $[5,28]$. This finding is in accordance with the outcomes of several studies that proposed that BC-based sealers were able to increase the fracture resistance comparable to that of the intact tooth $[29,30]$.

On the other hand, it was also found that root filling with the lateral condensation technique and Total fill root canal sealer is able to increase the fracture strength of the specimens but is not comparable to the un-instrumented sound tooth. Similar results were noted in the study conducted by Saw and Messer [31]. This finding can be explained by the fact that the finger spreader used for the lateral condensation technique generates stress on the canal wall that may weaken the tooth resulting in less fracture resistance [32]. Spreader design and applied forces are suggested as the contributing factors to the appearance of vertical root fractures during lateral compaction [31]. Moreover, the comparable fracture resistance among all the groups, which were sealed using TotalFill sealer and AH Plus sealer, further suggested that the difference in fracture load may be due to the difference in methodologies used [33]. Sağsen et al. and Mohammed \& Al-Zaka. in their studies revealed that difference in fracture strength among different sealer groups was due to variation in the technique opted for obturation [11,16].

The present in vitro study presented some inherent limitations. The diameter of the root was not standardized in the present study, which has a potential influence on the fracture resistance of the tooth. Moreover, the impact of canal shape cannot be overlooked as more tapered canals results in more dentin removal from the canal resulting in weakening of the specimens. Furthermore, the amount of dentinal tubules present in each specimen also influences the outcomes of root fracture resistance. As the present study was an in vitro experiment, more clinical-based studies should be conducted to validate the findings of the present study for clinical applications.

\section{Conclusions}

The use of TotalFill-BC sealer showed similar vertical root fracture resistance reinforcing effect as $\mathrm{AH}$ plus sealer in root canal treated teeth. Use of total fill-BC and $\mathrm{AH}$ Plus sealer in root canal treatment showed vertical root fracture resistance comparable to untreated natural teeth. Use of different obturation techniques (Single cone and lateral condensation technique) in the presence of sealers (AH plus and TotalFill) did not show a significant influence on vertical root fracture resistance.

Author Contributions: Conceptualization, M.F.A., K.H.A., F.A.A., A.M.A. and A.S.A.; methodology, M.F.A., F.A.A., K.H.A. and F.V.; validation, F.V., A.M.A. and T.A.; formal analysis, A.S.A., A.M.A., A.A.A. and K.H.A.; investigation, M.F.A., A.A.A. and F.V.; resources, T.A. and A.A.A.; data curation, F.V., K.H.A., O.M.A., A.A.A. and F.A.A.; writing—original draft preparation, F.V.; writing—review and editing, T.A. and F.V.; supervision, F.V., A.S.A., O.M.A. and A.M.A.; funding acquisition, T.A.; surgical assistance and data collection, revisions, A.A. All authors have read and agreed to the published version of the manuscript.

Funding: The authors are grateful to the Researchers supporting project at King Saud University for funding through Researchers supporting project No. (RSP-2019-44).

Institutional Review Board Statement: This study was submitted, reviewed, and approved by, Specialist Dental practice and Research Centre, Riyadh, Saudi Arabia (UDCRC/009-20). The ethical standards of the 1964 Helsinki declaration and national and/or institutional research committee 
were strictly followed while performing all the procedures. Additional information on the study was provided verbally by the study investigator or in a written format.

Informed Consent Statement: Consent was taken from individuals at teeth extraction.

Data Availability Statement: The data is available on contact from the corresponding author.

Acknowledgments: The authors are grateful to the Researchers supporting project at King Saud University for funding through Researchers supporting project No. (RSP-2019-44).

Conflicts of Interest: The authors declare no conflict of interest.

\section{References}

1. Touré, B.; Faye, B.; Kane, A.W.; Lo, C.M.; Niang, B.; Boucher, Y. Analysis of reasons for extraction of endodontically treated teeth: A prospective study. J. Endod. 2011, 37, 1512-1515. [CrossRef]

2. Bhat, S.; Hegde, S.; Rao, A.; Shaji Mohammed, A. Evaluation of resistance of teeth subjected to fracture after endodontic treatment using different root canal sealers: An in vitro study. J. Indian Soc. Pedod. Prev. Dent. 2012, 30, 305-309. [CrossRef] [PubMed]

3. Topçuoğlu, H.S.; Tuncay, Ö.; Karataş, E.; Arslan, H.; Yeter, K. In vitro fracture resistance of roots obturated with epoxy resin-based, mineral trioxide aggregate-based, and bioceramic root canal sealers. J. Endod. 2013, 39, 1630-1633. [CrossRef] [PubMed]

4. Uzunoglu-Özyürek, E.; Küçükkaya Eren, S.; Karahan, S. Effect of root canal sealers on the fracture resistance of endodontically treated teeth: A systematic review of in vitro studies. Clin. Oral Investig. 2018, 22, 2475-2485. [CrossRef]

5. Ribeiro, F.C.; Souza-Gabriel, A.E.; Marchesan, M.A.; Alfredo, E.; Silva-Sousa, Y.T.C.; Sousa-Neto, M.D. Influence of different endodontic filling materials on root fracture susceptibility. J. Dent. 2008, 36, 69-73. [CrossRef]

6. Karapinar Kazandag, M.; Sunay, H.; Tanalp, J.; Bayirli, G. Fracture resistance of roots using different canal filling systems. Int. Endod. J. 2009, 42, 705-710. [CrossRef]

7. Punjabi, M.; Dewan, R.G.; Kochhar, R. Comparative evaluation of fracture resistance of root canals obturated with four different obturating systems. J. Conserv. Dent. 2017, 20, 445-450. [CrossRef] [PubMed]

8. Zamin, C.; Silva-Sousa, Y.T.C.; Souza-Gabriel, A.E.; Messias, D.F.; Sousa-Neto, M.D. Fracture susceptibility of endodontically treated teeth. Dent. Traumatol. 2012, 28, 282-286. [CrossRef]

9. Sandikçi, T.; Kaptan, R.F. Comparative evaluation of the fracture resistances of endodontically treated teeth filled using five different root canal filling systems. Niger. J. Clin. Pract. 2014, 17, 667-672. [CrossRef]

10. Küçükkaya Eren, S.; Uzunoğlu-Özyürek, E.; Karahan, S. Influence of reciprocating and rotary instrumentation on microbial reduction: A systematic review and meta-analysis of in vitro studies. Restor. Dent. Endod. 2021, 46, e19. [CrossRef]

11. Mohammed, Y.T.; Al-Zaka, I.M. Fracture resistance of endodontically treated teeth obturated with different root canal sealers (A comparative study). J. Contemp. Dent. Pract. 2020, 21, 490-493. [CrossRef] [PubMed]

12. Mandava, J.; Chang, P.C.; Roopesh, B.; Faruddin, M.G.; Anupreeta, A.; Uma, C. Comparative evaluation of fracture resistance of root dentin to resin sealers and a MTA sealer: An in vitro study. J. Conserv. Dent. 2014, 17, 53. [CrossRef]

13. Phukan, A.H.; Mathur, S.; Sandhu, M.; Sachdev, V. The effect of different root canal sealers on the fracture resistance of endodontically treated teeth-in vitro study. Dent. Res. J. 2017, 14, 382. [CrossRef] [PubMed]

14. Dibaji, F.; Afkhami, F.; Bidkhori, B.; Kharazifard, M.J. Fracture Resistance of Roots after Application of Different Sealers. Iran. Endod. J. 2017, 12, 50. [CrossRef] [PubMed]

15. Ghoneim, A.G.; Lutfy, R.A.; Sabet, N.E.; Fayyad, D.M. Resistance to fracture of roots obturated with novel canal-filling systems. J. Endod. 2011, 37, 1590-1592. [CrossRef]

16. Sagsen, B.; Er, O.; Kahraman, Y.; Akdogan, G. Resistance to fracture of roots filled with three different techniques. Int. Endod. J. 2007, 40, 31-35. [CrossRef]

17. Yaman, S.D.; Alaçam, T.; Yaman, Y. Analysis of stress distribution in a vertically condensed maxillary central incisor root canal. J. Endod. 1995, 21, 321-325. [CrossRef]

18. Celikten, B.; Uzuntas, C.F.; Gulsahi, K. Resistance to fracture of dental roots obturated with different materials. Biomed. Res. Int. 2015, 2015. [CrossRef]

19. Jindal, R.; Singh, S.; Gupta, S.; Jindal, P. Comparative evaluation of apical extrusion of debris and irrigant with three rotary instruments using crown down technique-An in vitro study. J. Oral Biol. Craniofacial Res. 2012, 2, 105-109. [CrossRef] [PubMed]

20. El Hachem, R.; Khalil, I.; Le Brun, G.; Pellen, F.; Le Jeune, B.; Daou, M.; El Osta, N.; Naaman, A.; Abboud, M. Dentinal tubule penetration of AH Plus, BC Sealer and a novel tricalcium silicate sealer: A confocal laser scanning microscopy study. Clin. Oral Investig. 2018, 23, 1871-1876. [CrossRef]

21. Hovland, E.J.; Dumsha, T.C. Leakage evaluation in vitro of the root canal sealer cement Sealapex. Int. Endod. J. 1985, 18, 179-182. [CrossRef]

22. Loushine, B.A.; Bryan, T.E.; Looney, S.W.; Gillen, B.M.; Loushine, R.J.; Weller, R.N.; Pashley, D.H.; Tay, F.R. Setting Properties and Cytotoxicity Evaluation of a Premixed Bioceramic Root Canal Sealer. J. Endod. 2011, 37, 673-677. [CrossRef]

23. Dobrzańska, J.; Dobrzański, L.B.; Gołombek, K.; Dobrzański, L.A.; Dobrzańska-Danikiewicz, A.D. Virtual approach to the comparative analysis of biomaterials used in endodontic treatment. Processes 2021, 9, 926. [CrossRef] 
24. Ulusoy, Ö.I.A.; Nayr, Y.; Darendeliler-Yaman, S. Effect of different root canal sealers on fracture strength of simulated immature roots. Oral Surg. Oral Med. Oral Pathol. Oral Radiol. Endodontology 2011, 112, 544-547. [CrossRef] [PubMed]

25. Vilanova, W.V.; Carvalho-Junior, J.R.; Alfredo, E.; Sousa-Neto, M.D.; Silva-Sousa, Y.T.C. Effect intracanal irrigants on the bond strength of epoxy resin-based and methacrylate resin-based sealers to root canal walls. Int. Endod. J. 2012, 45, 42-48. [CrossRef]

26. Tay, F.R.; Pashley, D.H. Monoblocks in root canals: A hypothetical or a tangible goal. J. Endod. 2007, 33, 391-398. [CrossRef]

27. Ali, M.R.W.; Mustafa, M.; Bårdsen, A.; Bletsa, A. Fracture resistance of simulated immature teeth treated with a regenerative endodontic protocol. Acta Biomater. Odontol. Scand. 2019, 5, 30-37. [CrossRef] [PubMed]

28. Johnson, M.E.; Stewart, G.P.; Nielsen, C.J.; Hatton, J.F. Evaluation of root reinforcement of endodontically treated teeth. Oral Surg. Oral Med. Oral Pathol. Oral Radiol. Endodontology 2000, 90, 360-364. [CrossRef]

29. Gade, V.J.; Belsare, L.D.; Patil, S.; Bhede, R.; Gade, J.R. Evaluation of push-out bond strength of endosequence BC sealer with lateral condensation and thermoplasticized technique: An in vitro study. J. Conserv. Dent. 2015, 18, 124-127. [CrossRef]

30. Yendrembam; Mittal, A.; Sharma, N.; Dhaundiyal, A.; Kumari, S.; Abraham, A. Relative assessment of fracture resistance of endodontically treated teeth with epoxy resin-based sealers, AH Plus, MTA Fillapex, and Bioceramic Sealer: An In vitro study. Indian J. Dent. Sci. 2019, 11, 46. [CrossRef]

31. Saw, L.H.; Messer, H.H. Root strains associated with different obturation techniques. J. Endod. 1995, 21, 314-320. [CrossRef]

32. Shaheen, N.A.; Farag, A.M.; Alhadainy, H.A.; Darrag, A.M. Fracture resistance of endodontically treated roots using different preparation-obturation combinations. Tanta Dent. J. 2013, 10, 97-102. [CrossRef]

33. Lertchirakarn, V.; Palamara, J.E.A.; Messer, H.H. Load and strain during lateral condensation and vertical root fracture. J. Endod. 1999, 25, 99-104. [CrossRef] 